\title{
Connecting by Drawing: Use and Abuse
}

\author{
Luigi Cocchiarella
}

Abstract

Connection is everywhere. In the sub atomic as well as in the cosmic world. Connecting provides the glue without which elements could not reach the status of an object, and pieces of information could not make sense. In an interview about creativity knowledge and education, Mr. Piero Angela, one of the fathers of the Italian television, reminded me the invention of the radio by Guglielmo Marconi as a key case: looking at the first prototype, what did his invention actually consist of? he said. Surprisingly, connecting the antenna. That's it. Radio was made by assembling pre-existing technical components with an antenna. Similarly, since its origins Drawing is connecting network of lines based on a certain logic organization, and nowadays Drawing is more about connecting processes. Referring to the legend of the titan Prometheus, we can consider the connecting, as a privileged brain activity, the proper fire of knowledge. According to the conference topic, in this contribution we would also try to discuss about the connections between Prometheus and the other three legendary figures evoked in the call, that is, Metis, Mnemosyne, Hermes.

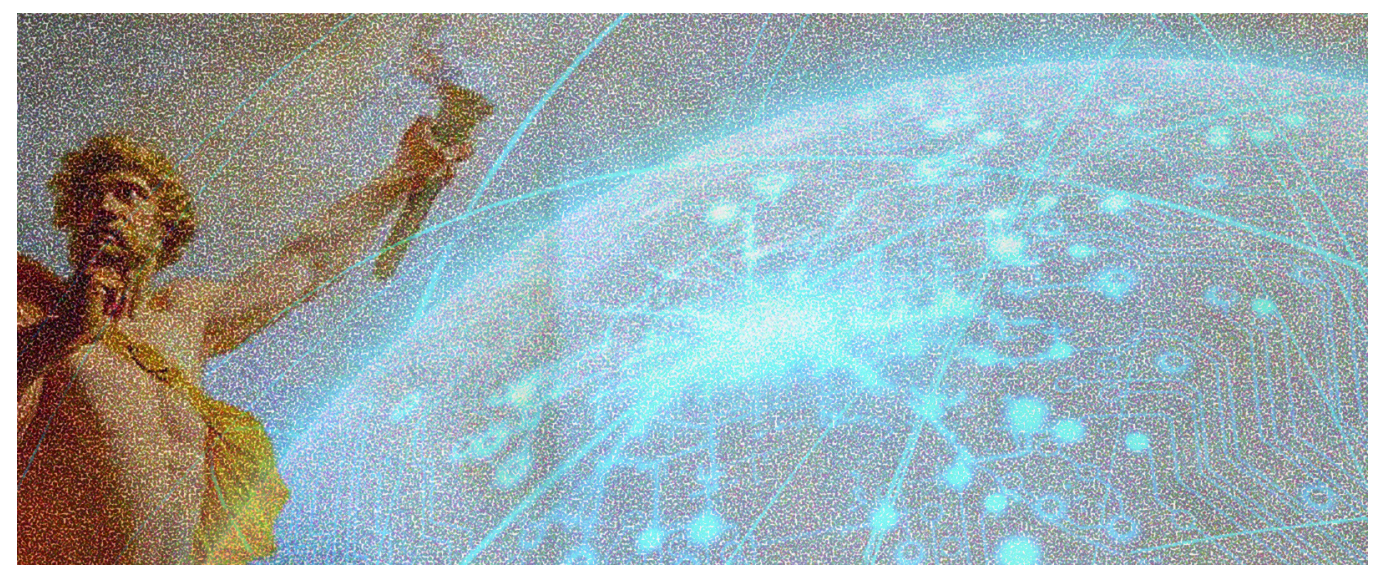




\section{Prometheus vs Prometheus - fire of digital}

Until few years ago, drawing was one of the most challenging task for students. Laying among science, technique and art, spatial imagination, logic, sensitivity, and manual abilities were required. Being talented in other fields like humanities or math was often of no help at all in this field. In other words, Drawing was frequently far for being attractive. The Digital provided a new connection between Geometry and Graphics, so that the two components became more easily manageable by dedicated commands. Geometry was visualized by graphic features, graphic features were geometry based. Logic of space and visual impact were now explicitly connected. Drawing was finally processed by connecting series of commands in order to reach the expected results. As soon as university opened the gate to the new tools, suddenly students' work became standardized and aesthetically comparable. Removing some operational obstacles, the digital resulted in a new extraordinary attractiveness of Drawing. At the same time new style and a new way of thinking about science of representation, education, and integrating knowledge was emerging. The new 'fire of digital' offered by Prometheus, fed series of new questions concerning theory and techniques of representation, which are still under discussion in the academic community, as well as outside the academic walls.

\section{Prometheus vs Metis - computing}

According to our classic Western tradition, if you have fire you can see, and if you can see you can understand and create. Then, Metis took relevant advantages from the 'fire of digital' recently put on stage by Prometheus. Advances in space configuration, invention, and transformations, made finally possible the manipulation of forms in real time, most of all in accordance with the interaction with various sets of parameters, even representative of intangible, or simply non formal data, increasing the information dimensions of the representations. Apart from the astonishing results achievable in terms of form finding and form definition, this fact was determining a paradigm shift in the approach to Drawing itself. Besides the advanced transformations achievable by digitally processing spatial forms, the mutation of mentality is to be mentioned as the most significant and revolutionary result. The new fire of Prometheus gave Metis the chance to change the approach to Drawing, whose semantics was no longer exclusively based on tracing lines or creating forms, but on managing and 'computing' several sets of inputs and information. Nowadays, computational design and information modelling provide more and more sophisticated semantic networks of data, which are image-based or, at least, image-referred. Let us say drawing-based or, at least, drawing-referred. Consequently, keyboards and other devices and sensors are nowadays competitors and cluster members of pencil and mouse in generating representations. And operators from the various other disciplinary fields orbiting around the architectural project also have the chance to access the architectural space modelling processes more directly.

\section{Prometheus and Mnemosyne - big data}

Memory is at the base of any identity or activity. Memory is also at the base of the digital, and 'big data' are supposed to become 'the' key topic in the near future, as the precondition for any activity carried out with the present devices. Memory is recorded in the documentation, and representations of memories can be reproduced, as well as organized in virtual systems. Our Western classic world was aware of that, at the point that Mnemosyne was celebrated as the mother of the Muses, guardians of art and inspiration. But the fast evolution of devices and programmes made us running faster and faster, and the attractiveness of the tools currently available is somehow promoting the false illusion that we can give up spending time on developing and fixing our own biological memory. At our convenience, 
in fact, we can easily fall into the web picking up fragments of information here and there, and then combining and recombining them in our work. Which sometime results in hybrid outcomes, revealing the purely temporary connection of the memories borrowed. Maybe artificial intelligence will help us to enhance the making of more meaningful operations. As human beings, in fact, our memories are more than lists of data, they are dependent on our overall cognitive experience, that is, they are profoundly connected with our life.

\section{Prometheus and Hermes - communication}

Representation is by definition very keen on narration. Any pile of Drawings and files developed for a space investigation or for a project, shows a narration, independently on the intention to achieve that result. Narration is having a new life in the era of visual media and social media. The immense archive of visual documents available, as well as the easy in producing new original images to put in the net with our devices, seem to push Drawing beyond the academic barriers, making it manageable by any people, independently on their skills. As Hermes was, indeed, the messenger of the gods, so visual 'communication' is increasingly widening its appealing operational spectrum in our human world, and its internal disciplinary articulation. The renewed fire of Prometheus is offering Hermes new opportunities and a new speed, let us say, the speed of light. But sometimes a question remains about sense and quality of the messages conveyed.

\section{Prometheus - fire and chain}

Metaphorically speaking, it is clear that no discussions would be possible without the light of Prometheus, which makes the image of the world possible, including the variety of its components, that is, visible and not visible, tangible and not tangible. On the other hand, in the light of the theoretical and technical bases metaphorically linked to Prometheus, we understand the role of appropriate applications (Metis), conscious use of memory (Mnemosyne), and communication (Hermes). Which can be considered as the components of the holistic system of knowledge and skills at the base of our disciplinary field, that is, the field of Drawing. Also including, once more, the superior benefit of virtuously 'connecting' these components. The fact is that the need for specializations and the excited rush promoted by the digital, is actually 'disconnecting' this system, either in the professional, or in the academic world, often generating four independent lines. Then, theory and techniques promoted by Prometheus tend to remain sterile investigations. Mutations of shape supported by Metis tend to end up in a context of dominant myopic experimental subjectivity. The building of memory enhanced by Mnemosyne hardly fertilizes knowledge and sensitivity of the operators. The narration of places and things related to Hermes is more and more frequently based on the data available as second hand materials, instead of on first hand data and original graphic materials intentionally prepared. Looking at music for instance, may help us to pose an interesting question on this latter and relevant point: if all the musicians would use covers instead of making new compositions, at the end, who will write the new music? In conclusion, Prometheus accomplished a second challenging mission with the 'fire of digital', giving us potentialities we have never had and hardly dreamt before. It is up to us to avoid abusing or misusing them, and most of all, it is up to us to avoid chaining him again.

\section{Credit}

Image: The 'connecting', myth and expectations. Graphic composition by the author. Sources of the images: Kronen Zeitung, February 23rd 2020: <https://www.krone.at/I686716> (Data network);Wikipedia (Prometheus steals fire, by H.F. Füger, 1817). 


\section{References}

Chiodo Simona (2008). La rappresentazione. Una risposta filosofica sulla verità dell'esperienza sensibile. Milano: Bruno Mondadori.

Cocchiarella Luigi (ed.). (20I5). The Visual Language of Technique. 3 Volumes. Cham Heidelberg New York Dordrecht London: Springer International Publishing.

Hemmerling Marco, Cocchiarella Luigi (eds.). (20 8). Informed Architecture. Cham: Springer International Publishing.

Ugo Vittorio (1994). Fondamenti della rappresentazione architettonica. Bologna: Esculapio.

Web source of the image: https://www.krone.at/I 6867I6, and Wikipedia.

\section{Author}

Luigi Cocchiarella, Politecnico di Milano, luigi.cocchiarella@polimi.it

To cite this chapter: Cocchiarella Luigi (2020). Connecting by drawing: use and abuse. In Arena A., Arena M., Brandolino R.G., Colistra D., Ginex G., Mediati D., Nucifora S., Raffa P. (a cura di). Connettere. Un disegno per annodare e tessere. Atti del $42^{\circ}$ Convegno Internazionale dei Docenti delle Discipline della Rappresentazione/Connecting. Drawing for weaving relationships. Proceedings of the 42th International Conference of Representation Disciplines Teachers. Milano: FrancoAngeli, pp. 338-341. 